\title{
La mejora de la expresión oral en los programas AICLE / Bilingües
}

\author{
M. a ISABEL HOMPANERA LANZÓS \\ Universidad Nacional de Educación a Distancia \\ mhompaner2@alumno.uned.es
}

\section{Resumen}

Este artículo presenta los resultados de un estudio longitudinal de casos llevado a cabo con 71 estudiantes, 28 alumnos AICLE y 43 alumnos no AICLE en un centro público dentro del Principado de Asturias sobre los efectos de AICLE en el aprendizaje de la lengua extranjera inglesa (producción oral). La evolución del aprendizaje lingüístico de ambos grupos se examina de Educación Primaria a Educación Secundaria Obligatoria a través de la aplicación de las Pruebas de Diagnóstico en Primaria y diferentes pruebas de seguimiento en Secundaria. Además de estas comparaciones intergrupales también se realizan análisis intragrupales para determinar la evolución del alumnado bilingüe y no bilingüe en los citados niveles educativos. En este caso la investigación tiene un enfoque ecléctico en cuanto a la recogida y análisis de datos se refiere (datos cualitativos y cuantitativos). Esta investigación muestra que la enseñanza bilingüe/AICLE mejora notablemente la competencia comunicativa en lengua extranjera de los estudiantes, pero es necesario seguir investigando qué factores son los que determinan esta mejoría dentro del programa AICLE / bilingüe y así seguir haciendo cambios y adaptaciones en la metodología actual en la enseñanza de idiomas para lograr un pleno desarrollo de la expresión oral en nuestros alumnos de lenguas extranjeras.

\section{Palabras clave}

AICLE; longitudinal; aprendizaje lingüístico; expresión oral. 


\title{
The improvement of oral skills in CLIL / Bilingual programs
}

\begin{abstract}
This piece or research presents the results of a longitudinal case study carried out among a group of 71 students, 28 of whom are CLIL students and 43 are Non CLIL students in one Secondary Education state school into the effects of CLIL method in the learning of English as a foreign language (oral skills).The evolution of the linguistic development of both groups is traced from Primary School to Secondary School through the administration of different tests. In addition to these intergroup comparisons, intragroup development is also examined to determine the evolution of both CLIL and non CLIL students across educational levels. In this case, the study has an eclectic approach as for the gathering and analysis of data. This study shows the CLIL approach improves the linguistic communicative competence of students but it is necessary to continue research to determine which factors are responsible for this improvement within the CLIL program and so implement the necessary changes in the process of FL teaching to achieve full development in our students' oral expression skills in a foreign language.
\end{abstract}

\section{Keywords}

CLIL; longitudinal; language attainment; oral expression.

Recibido el 13/05/2020

Aceptado el 28/10/2020 


\section{Introducción}

La enseñanza bilingüe se inicia en el curso 2004-2005 en Asturias como medio para alcanzar los objetivos impuestos en el Consejo Europeo de Barcelona 2002, donde se percibe la necesidad de mejorar la expresión oral de los alumnos y comunicarse en al menos dos lenguas extranjeras además de la materna, de forma que se facilite la movilidad entre todos los miembros de la Unión. Bajo el enfoque AICLE (Aprendizaje Integrado de Contenidos y Lenguas Extranjeras) se aprovechan los distintos recursos, estrategias y destrezas que desarrolla el alumno cuando aprende una lengua o una materia, a través de los currículos integrados de lenguas y de áreas no lingüísticas. De este modo se contribuye al desarrollo de una competencia comunicativa significativa que optimiza y facilita los aprendizajes posteriores.

El nuevo contexto europeo dominado por una economía de mercado basado en la sociedad del conocimiento hace evidente un cambio en las necesidades de educación y formación de los jóvenes europeos. El CoE (Consejo de Europa), desde su Departamento de Política Lingüística, propicia la promoción de la diversidad lingüística y del aprendizaje de lenguas, y contribuye a ello con el Marco Común Europeo de Referencia para las Lenguas (MCERL): aprendizaje, enseñanza, evaluación (2001), obra de referencia que orienta toda la política lingüística europea, así como con su herramienta complementaria: el Portfolio Europeo de las Lenguas. España participa de forma activa en todas y cada una de las iniciativas que promueve la Comisión. El Plan de Acción 2010-11 incorpora como objetivo específico el plurilingüismo.

Para dar respuesta a ese objetivo el MEC ha diseñado un «Programa integral de aprendizaje de lenguas extranjeras» (2010), acordado con las administraciones educativas. España se encuentra, a su vez, entre los países que fomentan el aprendizaje temprano de lenguas desde los niveles preescolares. Cabe destacar asimismo la expansión de la enseñanza bilingüe en la modalidad AICLE, fenómeno muy extendido en nuestro panorama educativo que ha dado lugar a un desarrollo prolífico en la investigación en el tema (Dalton -Puffer 2011 y Pérez Cañado, 2012). Sin embargo, la mayoría de los estudios publicados carecen de la perspectiva longitudinal o solo se centran en una etapa educativa, lo que ha llevado a muchos autores a hacer un llamamiento a este tipo de estudios dentro de la investigación AICLE, (véase: Bruton, 2011; Lasagabaster \&Ruiz de Zarobe, 2010; Pérez Cañado, 2016; Pérez Cañado Ráez Padilla, 2015; Ruiz de Zarobe, 2011); es aquí donde la presente investigación intenta dar respuesta ofreciendo los resultados de un estudio longitudinal del impacto AICLE en el desarrollo de la destreza de expresión oral en LE inglesa en dos cohortes de estudiantes a lo largo de dos etapas educativas :primaria y secundaria.

\section{Objetivos}

Con el fin de demostrar la mejora de la expresión oral que se produce en los alumnos que cursan asignaturas no lingüísticas siguiendo el enfoque metodológico de Aprendizaje Integrado de Contenidos en Lengua Extranjera (AICLE, Dalton-Puffer ,2011) dentro de los programas bilingües en los centros de Educación Secundaria Obligatoria, este estudio pretende dar respuesta a las siguientes preguntas de investigación: 
1. ¿Los contextos de enseñanza-aprendizaje AICLE y EFI (Enseñanza Formal del Inglés) promueven de igual forma el desarrollo de la competencia de la expresión oral en inglés como LE?

2. ¿Existen diferencias en la adquisición de la destreza oral entre los alumnos AICLE y los no-AICLE?

Este estudio pretende recabar información sobre cuáles son los mecanismos que favorecen el desarrollo de la competencia oral de los alumnos AICLE. Como se verá en la investigación presente, la metodología AICLE favorece la construcción de un aprendizaje por parte del alumno, este es agente activo que va construyendo su propio aprendizaje a través de la realización de tareas o tasks lo que conlleva una mejora no solo de las destrezas relacionadas con la lengua vehicular que está siendo usada para construir aprendizajes significativos sino en los aprendizajes de contenidos transmitidos en la L2.

\section{Método/ Metodología}

\subsection{Tipo de Investigación}

Este estudio es un ejemplo de investigación-acción pues se realiza con el claro propósito de mejorar una situación, y no tiene en su ánimo realizar ninguna generalización con pretensiones teóricas (Bisquerra ,1989). En nuestro caso el objetivo es mejorar la destreza de la expresión oral en los estudiantes. Para ello, se evaluarán los resultados de las estrategias utilizadas en el aula AICLE.

En este trabajo se requiere el uso de técnicas observacionales de aula y de anotaciones cualitativas (opinión de los padres / alumnos / profesores encuestados) aunque también se utilizarán ítems de tipo cuantitativo, que nos proporcionarán datos de tipo numérico sobre determinados aspectos: resultados en Expresión Oral / Expresión Escrita / Comprensión Oral en Inglés, Competencia Matemática y Conocimiento e Interacción con el Mundo Físico de los alumnos en las Pruebas de Diagnóstico en 4. ํㅡㄹ Educación Primaria 2013 en los centros de enseñanza primaria adscritos al IES objeto de estudio, así pues la investigación tiene un enfoque ecléctico en cuanto a la recogida y análisis de datos se refiere.

Esta combinación de datos objetivos con otros más subjetivos es necesaria para matizar aspectos de la realidad que son muy difíciles de cuantificar. Este enfoque ecléctico es a veces criticado por algunos autores, pero lo avalan muchos otros (Allwright y Bailey 1991; Ellis, 1984; Van Lier,1988).

\subsection{Selección de la población y muestra}

El IES objeto de análisis es un centro de Educación Secundaria de la zona rural-central de Asturias, anonimizado como condición para la cesión de los datos por la Consejería de Educación del Principado de Asturias y que tiene el programa Bilingüe AICLE en funcionamiento desde el curso 2007-08. La muestra que se estudia en este trabajo consta de 71 estudiantes del $1 .^{\circ}$ curso de ESO, grupo mixto formado a partir del alumnado de: $1 . \stackrel{\circ}{A}, 1 . \stackrel{o}{-}$ B y $1 .{ }^{\circ}$ C. En este grupo tenemos dos tipos de alumnado; 28 alumnos que forman parte del programa bilingüe o AICLE, en el IES distribuidos en $1 .^{\circ} \mathrm{A}, 1 .^{\circ} \mathrm{B}, 1 .{ }^{\circ} \mathrm{C}$, en lo sucesivo nos 
referiremos a él como grupo experimental y 43 alumnos que no siguen el programa bilingüe o AICLE, sino que siguen una enseñanza de dichas disciplinas en su L1, en lo sucesivo será el grupo de control; distribuidos en $1 .^{\mathrm{o}} \mathrm{A}, 1 . \stackrel{\mathrm{o}}{\mathrm{B}}, 1 .^{\mathrm{o}} \mathrm{C}$.

La cohorte que forma el grupo experimental son alumnos que han estado cursando las asignaturas de Música (1.ํㅡㄹ ESO) y Educación Física (1.ํㅡㄹ ESO) usando el inglés como lengua vehicular a la vez que reciben enseñanza formal de este idioma (EFI), proceden de un centro de Educación Primaria con enseñanzas bilingües donde han estudiado Conocimiento del Medio e Interacción con el Mundo Físico desde 2.ํ de Educación Primaria en inglés; por el contrario, los estudiantes del grupo de control han cursado enseñanzas en grupos ordinarios en un centro de Educación Primaria no bilingüe. Cabe destacar que las enseñanzas bilingües son opcionales en los centros de enseñanza Primaria y Secundaria pertenecientes a la Consejería de Educación del Gobierno del Principado de Asturias y que la inclusión en estos programas se hace de forma voluntaria.

En Educación Primaria en las secciones bilingües, no se aumenta el horario lectivo del alumnado, pero se imparte, además de las propias sesiones de idioma, un mínimo de dos sesiones semanales en la lengua extranjera (LE) en las áreas no lingüísticas seleccionadas por el propio centro, procurando una distribución horaria que permita al alumnado un contacto diario con dicha lengua. El grupo experimental había cursado la materia de Conocimiento e Interacción con el Mundo Físico usando el inglés como lengua vehicular en 2.․ㅜ 3.o, 4.ํo de Educación Primaria en el colegio bilingüe adscrito al IES hasta la fecha de la realización de las Pruebas de Diagnóstico de 2013.

En los datos recabados para la evaluación de diagnóstico de $4^{\circ}$ curso de Enseñanza Primaria se constata que el nivel socioeconómico y académico de las familias es medio en ambos grupos. Por tanto, sí, los dos grupos comparados son equivalentes. De la lectura de los datos obtenidos se desprende que los resultados de la investigación serían distintos de no haber enseñanza bilingüe en uno de ellos.

En cuanto a la exposición a la lengua inglesa de ambas cohortes, el IES objeto de estudio está situado en una villa de unos 5000 habitantes, la mayoría de ellos dedicados al sector primario, la escuela de idiomas o las posibilidades de interacción con la lengua inglesa se encuentran en la ciudad más cercana a $17 \mathrm{~km}$ de distancia. Por esto, no es hasta edades más avanzadas cuando la autonomía de los estudiantes les permite acceder a otro tipo de exposición a la lengua extranjera; se reduce, por lo tanto, su contacto con la lengua meta al contexto y ámbito escolar. De ahí que la investigadora haya considerado este un contexto idóneo para realizar el estudio, al no haber factores ambientales externos al centro escolar que condicionasen los datos. Las posibilidades de interacción con la lengua y cultura inglesa son ofrecidas por el IES y los dos colegios de la villa a todos los grupos (AICLE/NO AICLE) por igual.

\subsection{Hipótesis de investigación}

La profesora que realiza el trabajo de investigación ha observado en su experiencia diaria en el aula que los alumnos que cursan los programas de enseñanza bilingüe tienen una expresión oral en inglés mucho más fluida y una pronunciación más correcta y cuidada que aquellos alumnos que solo reciben instrucción formal de la lengua inglesa en la asignatura de LE, además utilizan estrategias de aprendizaje del idioma más efectivas y variadas que 
aquellos que no siguen el programa bilingüe. Es más, desarrollan una conciencia fonológica de la que adolecen el resto de los estudiantes. Por lo tanto, se formula la siguiente hipótesis: la expresión oral en inglés en alumnos de enseñanza bilingüe es superior a los que no reciben enseñanzas AICLE.

Una vez formulado la cuestión que pretendemos investigar o la hipótesis que queremos demostrar, debemos determinar las variables que vamos a controlar. En investigación educativa, como es este el caso, la variable dependiente es el rendimiento académico, la mejoría de la expresión oral en LE, las variables independientes son aquellos factores que afectan e inciden sobre la variable dependiente, en este caso la exposición del alumno a la LE en materias no lingüísticas y el uso de la LE como lengua vehicular para la transmisión de contenidos no lingüísticos, repercutiendo todo ello en la mejora de la competencia lingüística del alumno en general.

\subsection{Técnicas e instrumentos de recogida de datos y evaluación}

Con el fin de garantizar la fiabilidad del estudio se emplearán como instrumentos de medida los siguientes:

- Resultados de la Evaluación de Diagnóstico de 2013 en expresión oral en inglés realizadas por los alumnos de $4 .{ }^{\circ}$ curso de los dos colegios adscritos al IES, Centro 1 (no bilingüe) y Centro 2 (bilingüe), en lo sucesivo, alumnos que actualmente cursan 1. ESO en el IES objeto de análisis.

- Resultados de evaluación de expresión oral de la 1.ํ y 2.ํㅡㄹ Evaluación de los alumnos del grupo experimental y del grupo de control de 1. ․ ESO.

- 2 cuestionarios relativos al grado de satisfacción con el programa, hábitos de estudio, aspectos pedagógicos a alumnos y padres del grupo experimental.

- Cuestionario / entrevistas a los profesores de las ANL (Asignaturas no Lingüísticas).

Se espera constatar la evolución y el desarrollo de la expresión oral de los alumnos que estudian siguiendo la enseñanza AICLE, así pues, la siguiente tarea que nos queda por analizar es el porqué y el cómo; ¿son las metodologías AICLE favorecedoras de la expresión oral? Y si es así, ¿en qué difieren de las enseñanzas EFI (Enseñanza Formal del Inglés)? ¿Es el contexto AICLE el promotor e impulsor de la expresión oral?

Los resultados de este estudio constituirán el punto de partida para proseguir futuras líneas de investigación. Se intenta hacer el seguimiento de un determinado grupo de estudiantes (estudio de casos) durante un periodo largo de tiempo (4.ํㅡㄹ Educación Primaria 1. - ESO) para formular hipótesis que necesitarán ser sometidas, posteriormente, a comprobación con muestras más representativas.

\subsection{Etapas de la investigación}

Siguiendo los diferentes estadios en la investigación -Acción que Nunan (1992) describe, cabe destacar que: 
1. La investigación se inicia por parte del profesor y se deriva de un problema que debe ser tratado; en este caso la investigación objeto de análisis pretende demostrar la mejoría evidente que se produce en la expresión oral de los alumnos que estudian AICLE/ en los programas bilingües.

2. En el estudio colaboran la profesora del Instituto de Enseñanza Secundaria objeto del estudio y una investigadora de la Universidad Nacional de Educación a Distancia.

3. La profesora recaba datos objetivos en forma de escalas de valoración en expresión oral (y escrita) obtenidos por un sistema de rúbricas en las pruebas de Diagnóstico 2013 además de los datos ofrecidos por los resultados en expresión oral en los tests pasados a los alumnos de 1. ํㅡㄹ curso de ESO de enseñanza bilingüe.

4. Los resultados son analizados.

5. Finalmente, el proyecto retoma la cuestión planteada inicialmente y cierra el ciclo. Kemmis\& McTaggart (1988) hablan de la espiral del método de Investigación-Acción, en el sentido en que se vuelve a la cuestión inicial, se reflexiona sobre ella y se abren nuevos caminos en la investigación.

Otro dato importante a tener en cuenta en toda investigación es la idea del control de calidad. Dos parámetros miden la calidad: la fiabilidad (reliability) y validez (validity). La fiabilidad nos recuerda que hemos de mantener la consistencia entre informadores y distintos observadores en el tiempo, i.e. si se repitiera nuestra investigación en otro momento, con otros informadores, observadores e investigadores, los resultados deberían ser los mismos. La validez (validity) representa, a su vez, la búsqueda de la verdad. ¿Son verdad los mismos resultados para otras poblaciones?

Un procedimiento recomendable para contrastar los datos en investigación etnográfica es la triangulación. En este trabajo de investigación la triangulación adopta las tres modalidades ya que:

- Los datos son recogidos en diferentes tiempos (4. EP, 1. ESO).

- Interviene más de un profesor en la recogida de datos (la profesora autora de la investigación, el profesor que pasa las Pruebas de Diagnóstico, los profesores

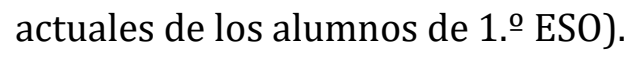

- Los métodos y técnicas de recogida de datos son variados: cuestionarios, escalas de observación, test, entrevistas.

\section{Resultados}

\subsection{Descripción y análisis de datos}

El objetivo principal del trabajo de investigación es demostrar la mejora evidente que se produce en la expresión oral de los alumnos que cursan el programa bilingüe en el IES objeto de estudio. Para dar respuesta a las preguntas de investigación expuestas en el apartado 2, se usarán los datos recabados de las tres cuestiones siguientes: 
1. ¿Qué grado de competencia en expresión oral en lengua inglesa alcanza el alumnado después de 6 años de haber seguido el programa bilingüe?

2. ¿Cuál es la percepción que tienen los alumnos, las familias y los profesores respecto al programa bilingüe?

3. ¿En qué grado se consiguen los objetivos de aprendizaje propuestos en el programa bilingüe?

Las respuestas a estas preguntas determinarán si los contextos de enseñanzaaprendizaje AICLE y EFI (Enseñanza Formal del Inglés) promueven de igual forma el desarrollo de la competencia de la expresión oral en inglés como LE y si existen diferencias en la adquisición de la destreza oral entre los alumnos AICLE y los no-AICLE, objetivos de la presente investigación.

\subsection{Recogida de datos}

Para dar respuesta a estas preguntas de investigación se han utilizado los instrumentos de recogida de datos ya mencionados en el apartado 3.2 y que constituyen instrumentos ejemplo de fiabilidad, dimensionalidad e invarianza. Las rúbricas de corrección exhaustivas explicitan y ponderan los criterios de corrección y de codificación de la respuesta dando resultados discriminantes y significativos.

\subsection{Análisis de resultados}

\subsubsection{Resultados de la Evaluación de Diagnóstico 2012-2013}

Los resultados de la Evaluación de Diagnóstico de Educación Primaria 2013, todos ellos anonimizados y referidos como Centro1, Centro 2, han sido proporcionados por la Dirección General de Ordenación Académica e Innovación Educativa, Servicio de Evaluación Educativa.

En todas las escalas se han recuperado más del $90 \%$ de los casos totales. Los datos son representativos del curso y centro correspondientes. Se ha de tener en cuenta lo siguiente:

- Las escalas totales (conjunto de Asturias) de cada competencia tienen como media 500 puntos y desviación típica 100 [N (500,100)]. Por tanto, el total de la tabla se refiere a los 2 centros seleccionados.

- Las pruebas de Expresión Oral y Escrita se puntúan por un sistema de rúbricas, por lo que los resultados pueden contener un "efecto del corrector", cuestión que debiera afectar menos al resto de las escalas donde el formato de los ítems es cerrado o, como mucho, de respuesta abierta corta o muy corta y se corrigen según unos libros de codificación cerrados.

- En el Centro 1 el error típico de la media duplica en error típico del Centro 2 en algunas escalas. Eso es debido a que el Centro 1 aporta pocos casos. Pese al tamaño de los errores típicos y la pequeña $\mathrm{N}$ se advierten diferencias estadísticamente significativas entre los centros en todas las escalas menos precisamente en expresión oral en la asignatura de Inglés. 
Tabla 1. Resultados Prueba de Diagnóstico 2013. Educación Primaria

\begin{tabular}{|l|l|l|l|l|l|l|l|}
\hline \multirow{2}{*}{$\begin{array}{l}\text { ID } \\
\text { Centro }\end{array}$} & $\begin{array}{l}\text { Inglés } \\
\text { Expresión } \\
\text { Oral }\end{array}$ & $\begin{array}{l}\text { Inglés } \\
\text { Expresión } \\
\text { Escrita }\end{array}$ & $\begin{array}{l}\text { Inglés } \\
\text { Compresión } \\
\text { Oral }\end{array}$ & $\begin{array}{l}\text { Inglés } \\
\text { Compresión } \\
\text { Escrita }\end{array}$ & $\begin{array}{l}\text { Competencia } \\
\text { Matemática }\end{array}$ & $\begin{array}{l}\text { Conocimiento } \\
\text { e Interacción } \\
\text { con el Mundo } \\
\text { Físico }\end{array}$ \\
\hline \multirow{4}{*}{ Centro 1 } & Media & 424,5 & 436,3 & 357,5 & 369,3 & 403,1 & 398,7 \\
\cline { 2 - 8 } & Error típ. de la media & 27,9 & 17,0 & 23,0 & 22,9 & 29,9 & 26,4 \\
\cline { 2 - 8 } & Desv. típ. & 96,8 & 58,9 & 79,6 & 79,5 & 99,2 & 87,6 \\
\cline { 2 - 8 } & N & 12 & 12 & 12 & 12 & 11 & 11 \\
\hline \multirow{5}{*}{ Centro 2 } & Media & 478,3 & 516,9 & 486,3 & 482,4 & 494,7 & 501,3 \\
\cline { 2 - 8 } & Error típ. de la media & 18,7 & 18,4 & 14,6 & 15,1 & 14,9 & 13,7 \\
\cline { 2 - 8 } & Desv. típ. & 119,7 & 117,9 & 93,7 & 96,4 & 95,4 & 87,6 \\
\cline { 2 - 8 } & N & 41 & 41 & 41 & 41 & 41 & 41 \\
\hline \multirow{5}{*}{ Total } & Media & 466,2 & 498,7 & 457,1 & 456,8 & 475,3 & 479,6 \\
\cline { 2 - 8 } & Error típ. de la media & 16,0 & 15,4 & 14,4 & 14,3 & 14,2 & 13,4 \\
\cline { 2 - 7 } & Desv. típ. & 116,3 & 112,2 & 105,1 & 103,8 & 102,4 & 96,5 \\
\cline { 2 - 7 } & N & & & & & & \\
\hline
\end{tabular}

Como se puede observar en la tabla.1 la destreza de expresión oral es la destreza en la que menores diferencias se advierten, no obstante, es significativo la puntuación en Conocimiento e Interacción con el Mundo Físico pues en el centro bilingüe la puntuación es muy superior al del centro no lingüístico; señalar que precisamente es esa una de las asignaturas que los alumnos del Centro bilingüe reciben usando la lengua extranjera como lengua vehicular. Por lo que se constata una mejor asimilación de los conocimientos adquiridos utilizando la LE como lengua vehicular.

Cabe destacar que, dentro de las destrezas de la competencia lingüística en inglés, la de expresión oral es la que presenta menor diferencia de niveles entre los dos centros, ambos están por debajo de la media que se sitúa en 500 puntos, lo que quiere decir que estos alumnos no alcanzarían el nivel esperable. Si bien cabe señalar que en los primeros estadios del enfoque AICLE son las destrezas de recepción las que adquieren mayor relevancia y las que primero se desarrollan. Estos alumnos de 4. ${ }^{\mathrm{o}}$ curso de Educación Primaria han recibido dos horas de formación AICLE semanales (Conocimiento e Interacción con el Mundo Físico) durante los cursos 2.ำ 3.ํy 4.ํde Educación Primaria.

En cuanto a los mejores resultados en la competencia matemática; son alumnos que muestran un alto grado de motivación para el estudio y que han desarrollado otro tipo de estrategias y formas de aprender fruto de su experiencia AICLE. La bibliografía aportada y consultada por la investigadora (Coonan, 2006; Coyle et al., 2010,) le permite relacionar la metodología y el proceso de enseñanza-aprendizaje característico del método AICLE, con el desarrollo en los alumnos de una capacidad crítica, más analítica, que busca, un enfoque más práctico del aprender a través del descubrimiento, lo que puede favorecer el proceso cognitivo y la motivación (Atkinson, 1964;Valle, 2007; Nuñez, 2009) necesaria en las ciencias y por ende, en las matemáticas; lo que pudiera llevarles a obtener mejores resultados. Asimismo, la mejora de la competencia comunicativa en lengua extranjera y en la lengua materna, por transferencia, conlleva una mejoría de la comprensión del lenguaje matemático que en estadios iniciales es imprescindible para resolver la tarea. 


\subsubsection{Pruebas objetivas de expresión oral}

La nota que cada alumno ha alcanzado en competencia comunicativa, expresión oral, se ha obtenido calculando la media aritmética de las notas logradas en las diferentes pruebas objetivas. Una vez introducidos los datos en el programa Excel se obtiene la gráfica con la distribución y desviación típica de los resultados, así como la evolución de notas de la 1.a a la 2.ำ evaluación. El objetivo lingüístico esperable para los alumnos de 1.ํㅜ curso de ESO es de A2 según el MCERL.

En la siguiente gráfica, figura 1: evolución de las calificaciones en la expresión oral de alumnos bilingües en la 1.ำ y 2.ำ evaluación, se muestra cómo los alumnos de bilingüe en su mayoría, el 70 \%, mejora sus calificaciones en expresión oral en la 2.e evaluación respecto a la 1.o , solo el $30 \%$ empeora o baja su rendimiento. Además, la desviación típica es baja por lo que las diferencias entre los rendimientos de los diferentes alumnos no son significativas.

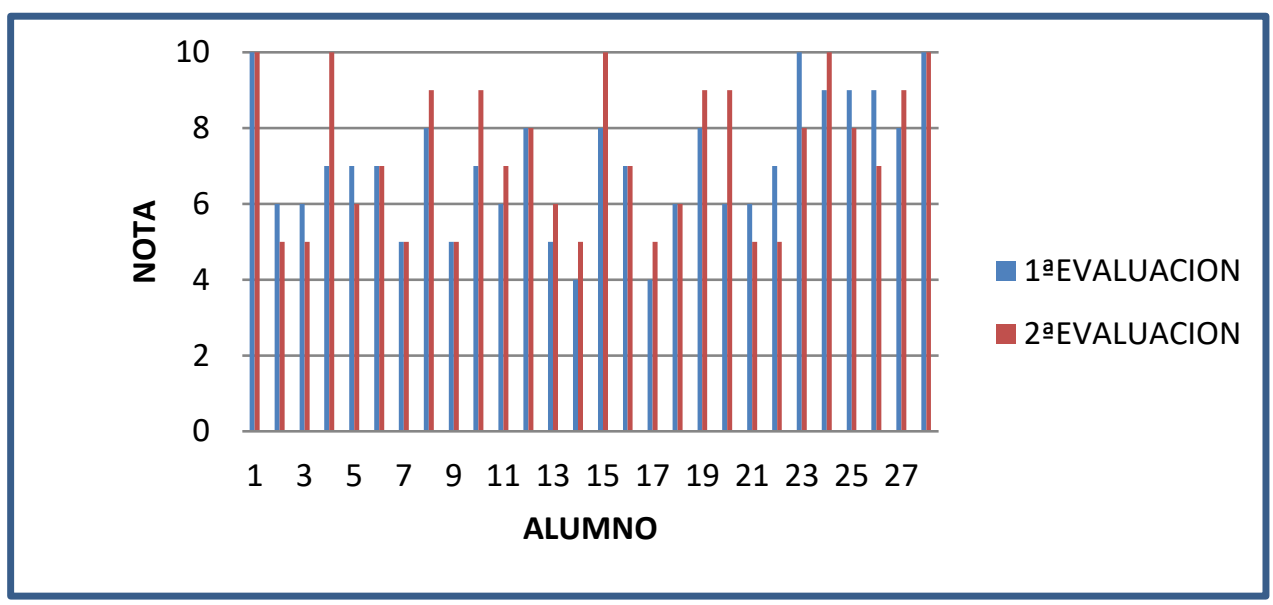

Figura 1. Evolución calificaciones en expresión oral de alumnos bilingües en la 1. y 2.으 evaluación

En los alumnos del grupo bilingüe el promedio de sus calificaciones es de 7,07 en la 1. $\stackrel{\text { o }}{ }$ evaluación, mientras que en la 2. evaluación sube a 7,32 sobre 10. Es una mejoría relevante, además no hay ningún alumno que no haya conseguido nota positiva en la 2.ํ evaluación. Se da un $100 \%$ de aprobados.

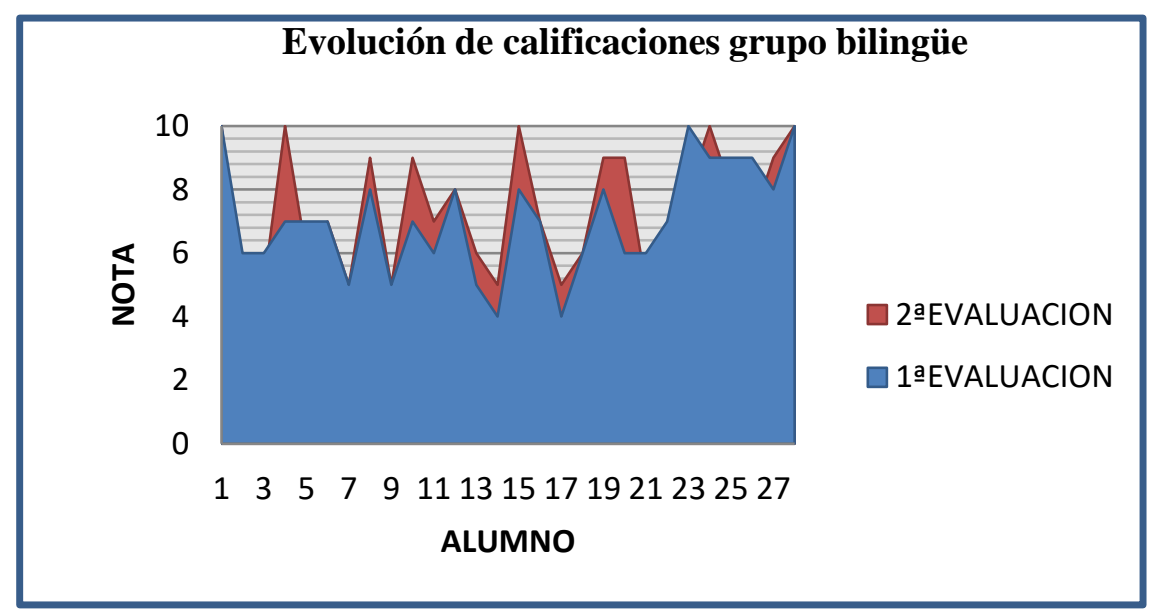

Figura 2. Evolución calificaciones en expresión oral de alumnos bilingües en la 1. y 2.0 evaluación 
A continuación, se analizan los resultados de las calificaciones obtenidas en las pruebas de expresión oral en los grupos no bilingües: $1 . \stackrel{\circ}{\mathrm{A}}, 1 . \stackrel{\circ}{\mathrm{B}} \mathrm{B}, 1 . \stackrel{\mathrm{o}}{\mathrm{C}}$ :

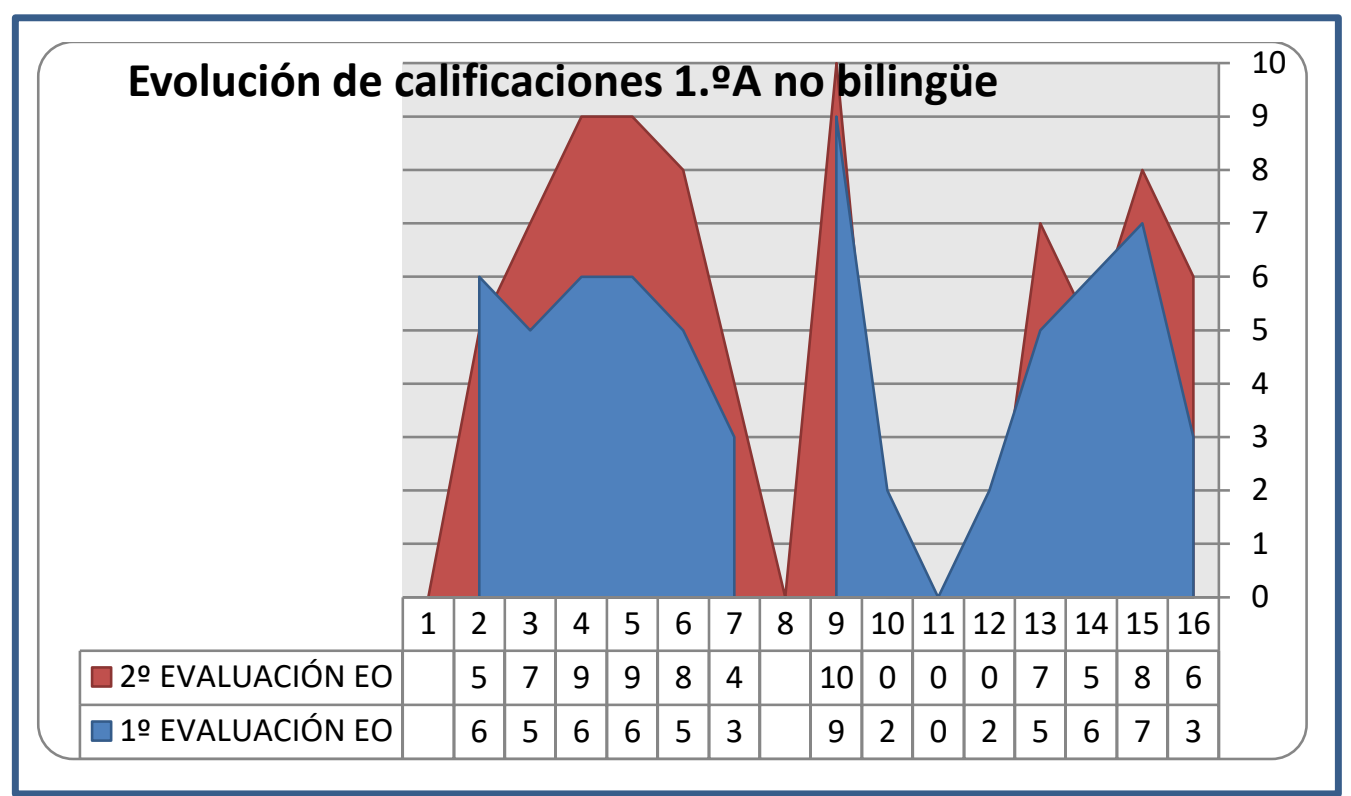

Figura 3. Evolución de notas en expresión oral en el grupo 1.․ A no bilingüe

Como se puede observar en la fig. 3 el grupo no bilingüe 1.ㅇ A muestra unas calificaciones muy bajas, el promedio en la 1.o evaluación es de 4,64 y en la 2.ํ de 5,57. El 28,57 \% de los alumnos suspenden en el 2.ำ evaluación, las calificaciones asimismo son muy bajas.

Veamos ahora la evolución de calificaciones en el grupo 1.ํㅡ B no bilingüe:

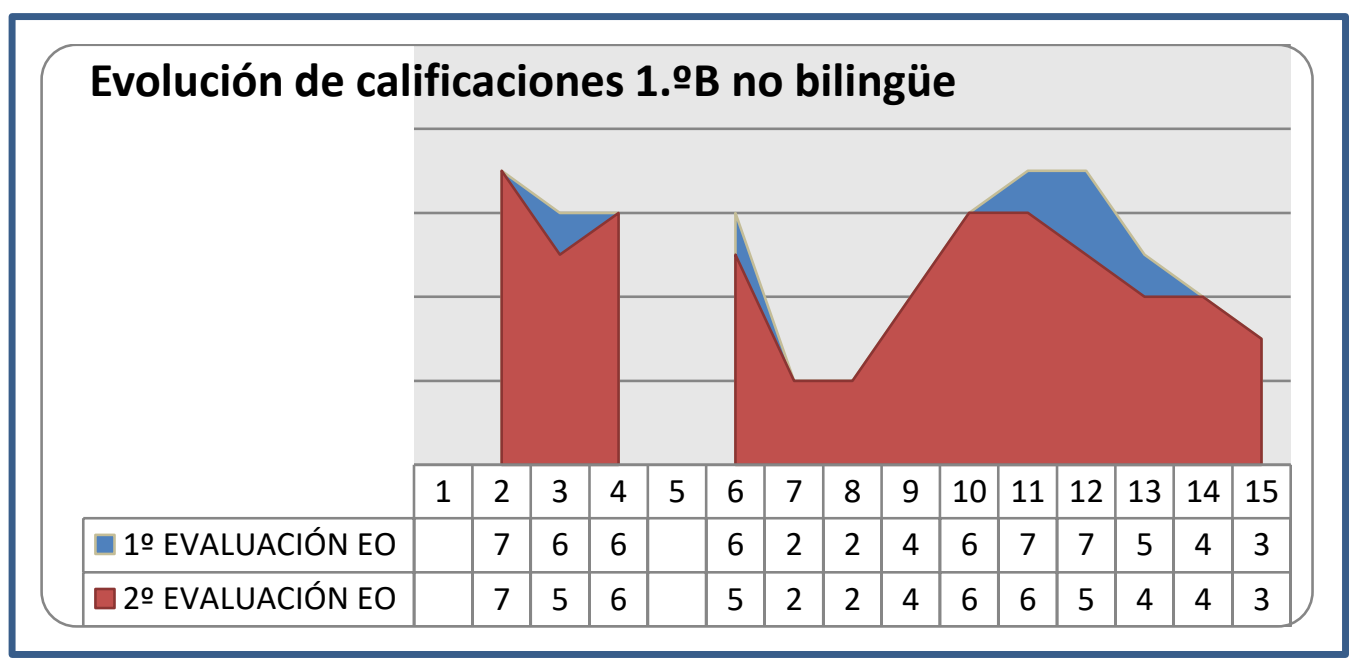

Figura 4. Evolución de notas en expresión oral en el grupo 1ํㅡ no bilingüe

Como se observa en la fig. 4 el grupo no bilingüe de $1 .^{\mathrm{o}} \mathrm{B}$ tiene un promedio de 5 en la $1 .^{\mathrm{o}}$ evaluación, mientras que en la 2.․e evaluación desciende a 4,54. Suspende el $46 \%$ de los 13 alumnos que conforman el grupo. Las calificaciones son muy bajas, siendo la nota máxima un 7 sobre 10 puntos.

Analizamos, a continuación, los resultados obtenidos en el grupo $1 .^{\mathrm{o}} \mathrm{C}$, no bilingüe: 


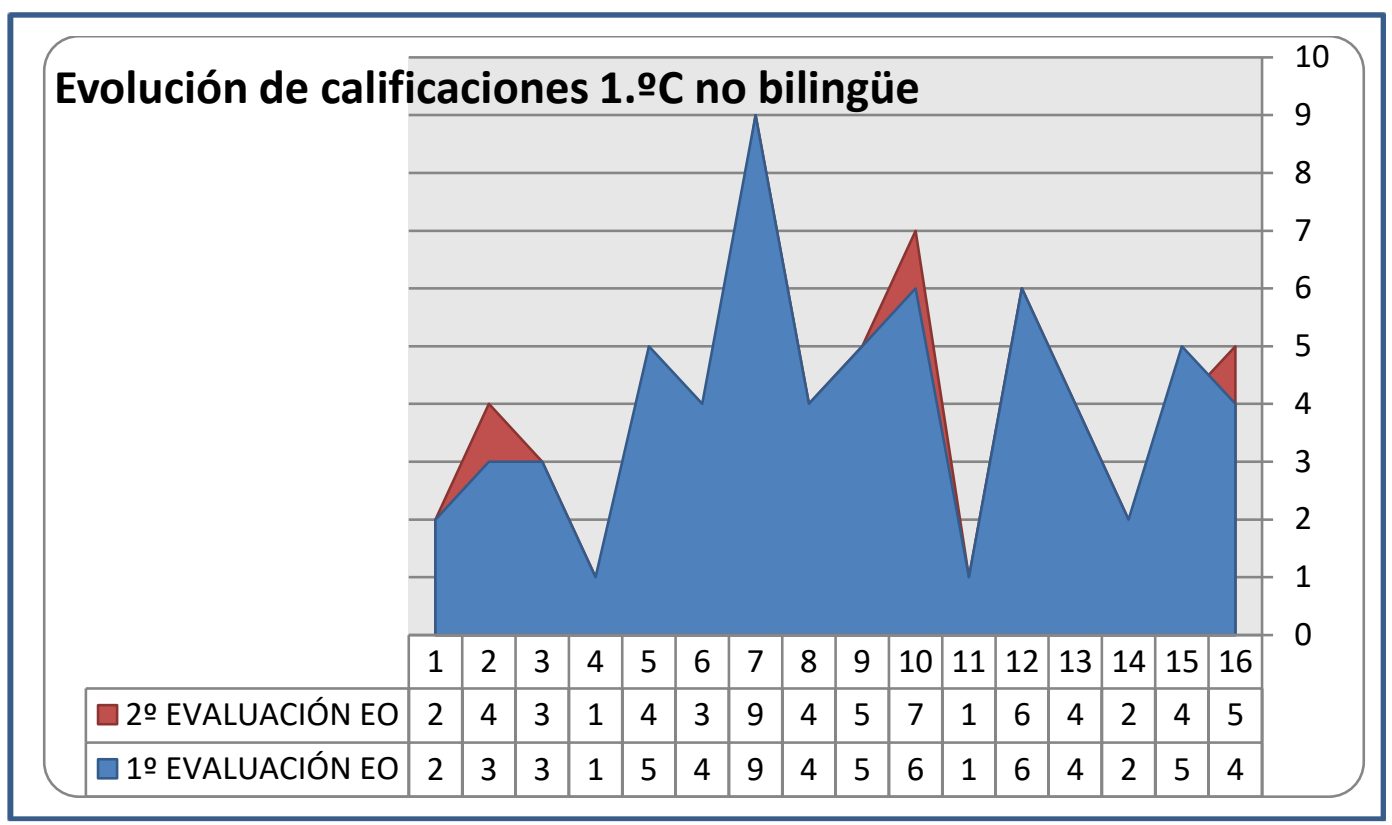

Figura 5. Evolución de notas en expresión oral en el grupo 1. o C no bilingüe

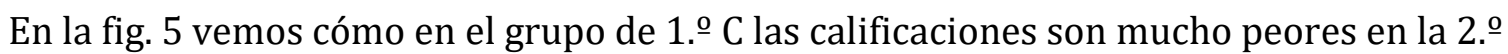
evaluación, solo el $27 \%$ de los alumnos aprueban la evaluación. El promedio de las calificaciones es de 3,9. En la 1.o evaluación el promedio es de 4 sobre 10 por lo que, lejos de mejorar su expresión oral, en estos alumnos empeora.

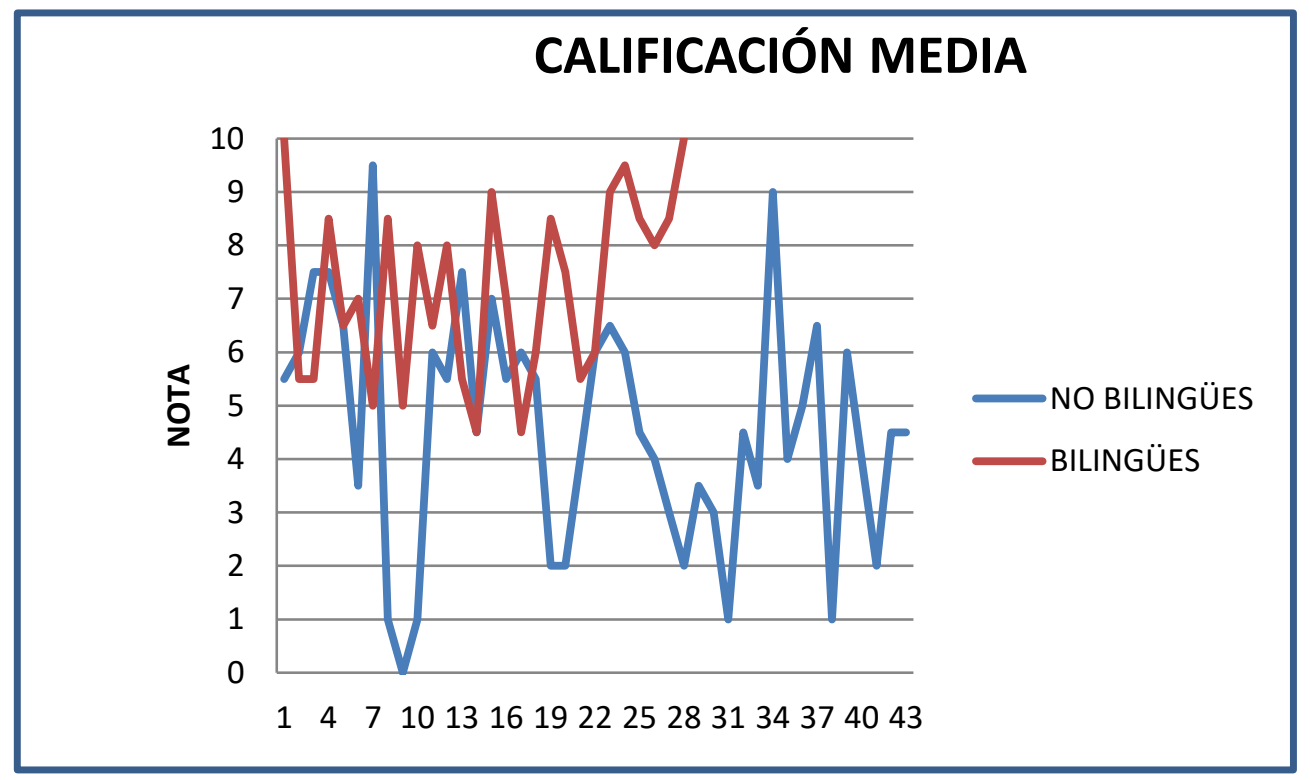

Figura 6. Comparación calificaciones en expresión oral entre el grupo bilingüe y los no bilingües

En la gráfica, fig.6, se observa claramente la evolución ascendente de las calificaciones de los alumnos que siguen el programa bilingüe. Por el contrario, las calificaciones del grupo bilingüe son muy variables y tienen una evolución muy negativa.

Como se puede ver en la fig.7, la desviación típica de los alumnos no bilingües es bastante superior a la de no bilingües, lo que nos da idea de que el grupo no bilingüe es bastante heterogéneo. 


\begin{tabular}{|l|l|l|l|}
\hline & Error típico de la media & Desviación & Número \\
\hline Bilingües & 0,3205271 & 1,6960700 & 27 \\
\hline No bilingües & 0,341507 & 2,239408 & 43 \\
\hline
\end{tabular}

Figura 7. Error típico de la media y desviación en calificaciones grupos bilingüe y no bilingües

\subsubsection{Cuestionarios a padres, alumnos y profesores de enseñanza bilingüe}

El análisis de las respuestas a los cuestionarios actitudinales se ha realizado obteniendo la media aritmética de todas las respuestas emitidas para cada variable y creando una tabla de datos mediante la hoja de cálculo Excel lo que nos ha permitido obtener los gráficos relacionados. En el presente artículo se recogen algunas de las respuestas más significativas para la investigación.

Cuestionario a padres. El primer cuestionario se hace a los padres y tutores de los alumnos, como parte indispensable en todo el proceso de enseñanza-aprendizaje, es importante conocer la percepción que las familias tienen del programa, su grado de satisfacción con este, así como las expectativas que tienen de él. El cuestionario consta de 20 preguntas; las cinco primeras son de tipo demográfico, sociocultural, de manera que tengamos una percepción general del contexto socioeconómico de los alumnos que forman el grupo. Las 14 preguntas siguientes están graduadas por una escala de intensidad en las que el padre o madre debe valorar de 1 a 5 (siendo 1 el mínimo y 5 el máximo) diferentes características del programa o su percepción del mismo. Las escalas de intensidad o de apreciación son un tipo de escala de actitud que estructura las opiniones bajo formas de respuesta en abanico, según la evolución o grados de un continuum de actitud (Murillo, 2006).

De la encuesta se desprende que el $58 \%$ de los padres encuestados tienen una formación universitaria, la mitad habla inglés, lo que puede constituir una motivación para el aprendizaje del idioma ya que el contexto familiar lo favorece en este caso. A su vez, viven a menos de $1 \mathrm{~km}$ de distancia del centro, lo que facilita la participación del alumnado en actividades extraescolares relacionadas con el aprendizaje del idioma.

La segunda parte del cuestionario, preguntas 6 a 19, se refiere a aspectos actitudinales respecto al programa. De su lectura se desprende que la totalidad de los padres están muy satisfechos de que sus hijos sigan el programa bilingüe, el 88 \% consideran que la formación impartida en el programa es buena, asimismo valoran muy positivamente la calidad del profesorado (88\% están satisfechos con ella). El $100 \%$ de los padres encuestados consideran muy importante que adquieran una buena competencia comunicativa en el idioma para el futuro profesional y académico de sus hijos. El $84 \%$ de los padres encuestados cree que la expresión oral de sus hijos ha mejorado sustancialmente desde que está en el programa bilingüe.

Destaca que el $80 \%$ de los padres animan a que sus hijos hablen en inglés fuera del centro escolar, sin embargo, solo un $42 \%$ procuran que sus hijos vean la televisión en inglés, o un $38 \%$ de ellos compran libros o revistas en la lengua meta. El porcentaje asciende ligeramente cuando se trata de escuchar la radio o la música en inglés (58 \%).

Destaca positivamente la percepción por parte de los padres de que la administración educativa apoya suficientemente el programa (80 \%), dato que contrasta con otros estudios llevados a cabo en otras administraciones educativas. El $80 \%$ de los padres consideran que 
el centro organiza suficientes actividades complementarias relacionadas con el programa. Finalmente, un $84 \%$ de los padres recomendaría el centro a otros padres.

La última pregunta del cuestionario era abierta para que los padres sugirieran posibles vías de mejora en el programa, a lo que cabe mencionar el deseo de que se lleven a cabo más intercambios y estancias formativas en el extranjero tanto para estudiantes como para los profesores implicados en su docencia.

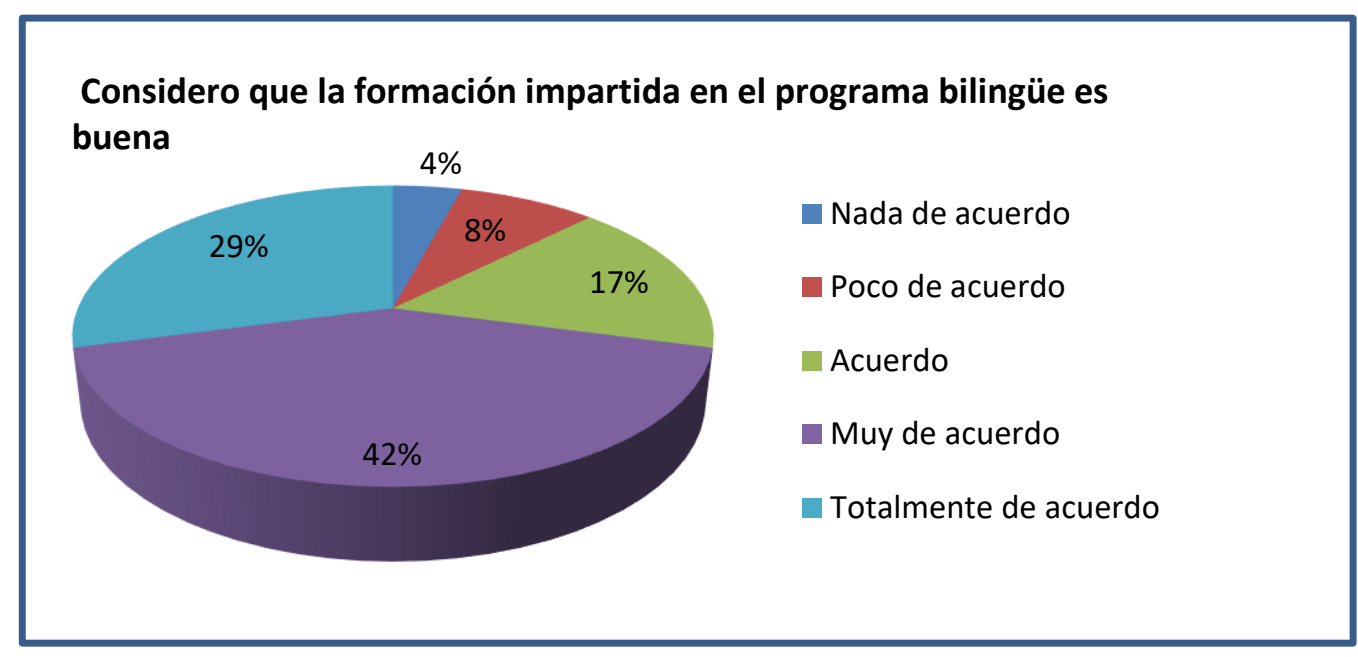

Figura 8. Encuesta realizada a padres del grupo

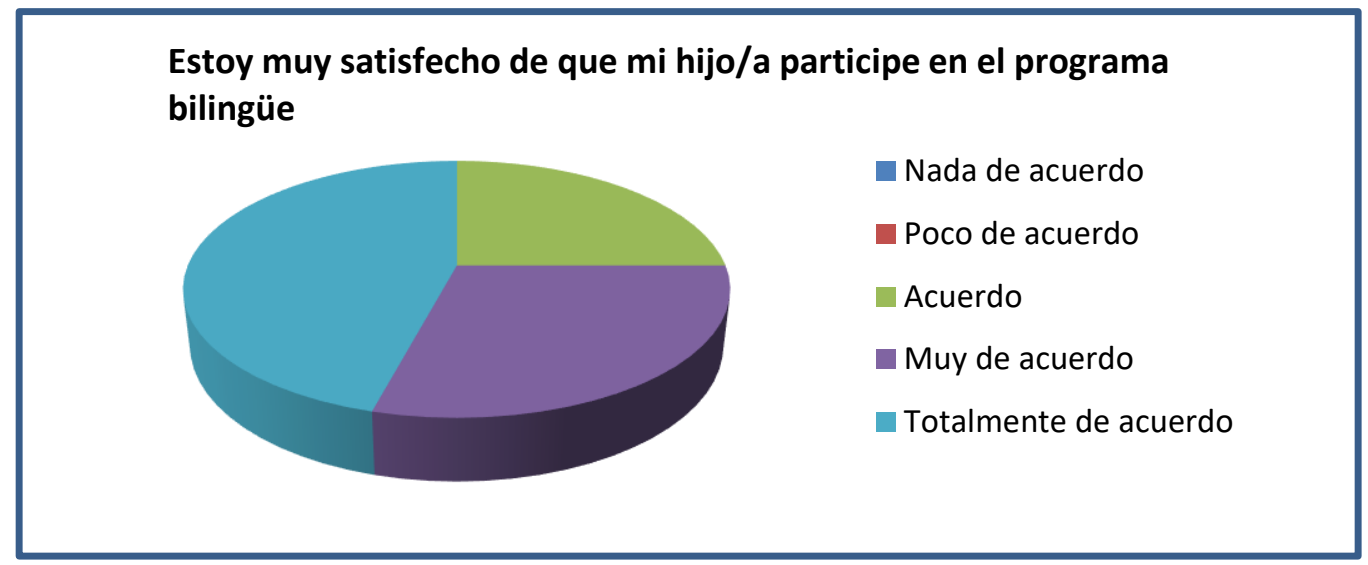

Figura 9. Encuesta realizada a padres del grupo

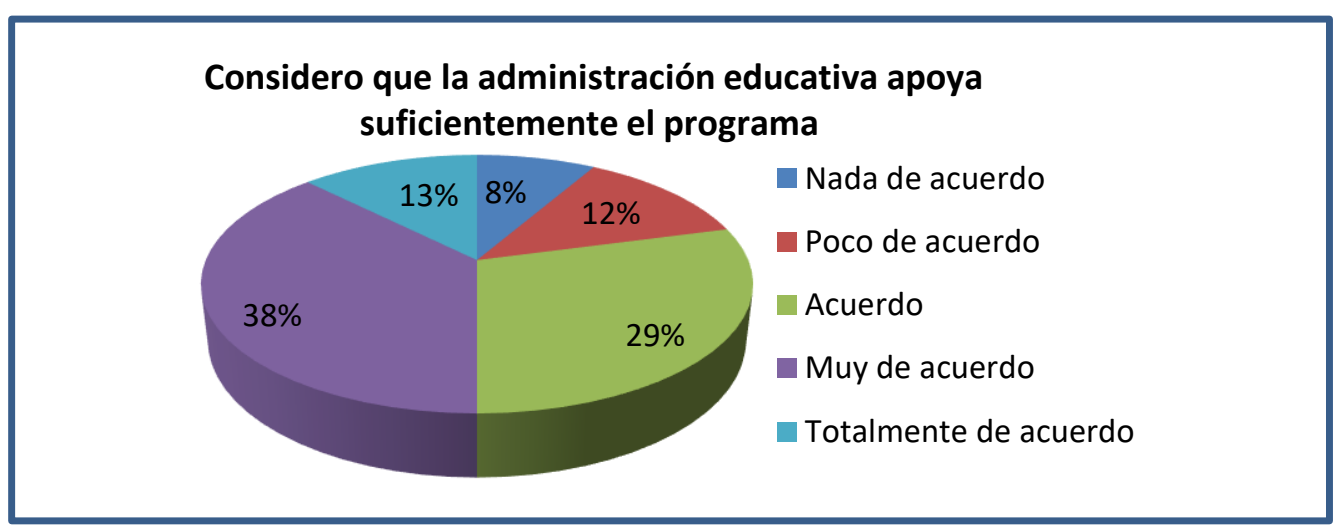

Figura 10. Encuesta realizada a padres del grupo bilingüe, pregunta 16 
Cuestionario a alumnos. El segundo cuestionario se realiza a otro componente importante y crucial del proceso enseñanza-aprendizaje: los alumnos, ellos son los protagonistas y principales constructores de contenidos en el enfoque AICLE. La motivación y una actitud positiva de los alumnos es clave para el éxito del programa y para proseguir con el aprendizaje autónomo en un futuro. Además, se pretende despertar la conciencia cultural en esta sociedad global.

Los alumnos responden a 21 preguntas relativas a su perfil académico, las estrategias que utilizan para aprender una LE y su visión del programa en el que participan. En general los alumnos consideran muy importante el aprendizaje del idioma con fines académicos y profesionales en el futuro. Esta alta motivación viene principalmente de la influencia familiar que lo considera un factor clave para el éxito profesional futuro. Los alumnos muestran gran entusiasmo por el programa y manifiestan que se encuentran contentos de participar en él.

Destaca su percepción sobre su nivel de dominio de la LE, el $100 \%$ de los alumnos encuestados considera que tiene un nivel medio o alto del idioma meta. El $60 \%$ de ellos se creen buenos o muy buenos estudiantes, lo que demuestra que tienen motivación y que esta se mantiene, para el estudio. Además, consideran que es importante aprender otras lenguas para comprender mejor su lengua nativa el $81 \%$. El $100 \%$ manifiesta estar contento por participar en el programa.

Los alumnos muestran una imagen positiva de sí mismos; se consideran estudiantes competentes y responsables, que obtienen buenos resultados académicos y cumplen con sus obligaciones académicas, estudiando en casa y haciendo las tareas encomendadas a tiempo. Un $78 \%$ declara sentirse más seguro hablando en inglés.

Los alumnos del grupo bilingüe, $81 \%$, son conscientes de que aprender una LE les ayuda a comprender mejor su lengua y a expresarse también mucho mejor en su lengua materna; se puede deducir que aplican estrategias comunicativas que transfieren de una lengua a otra.

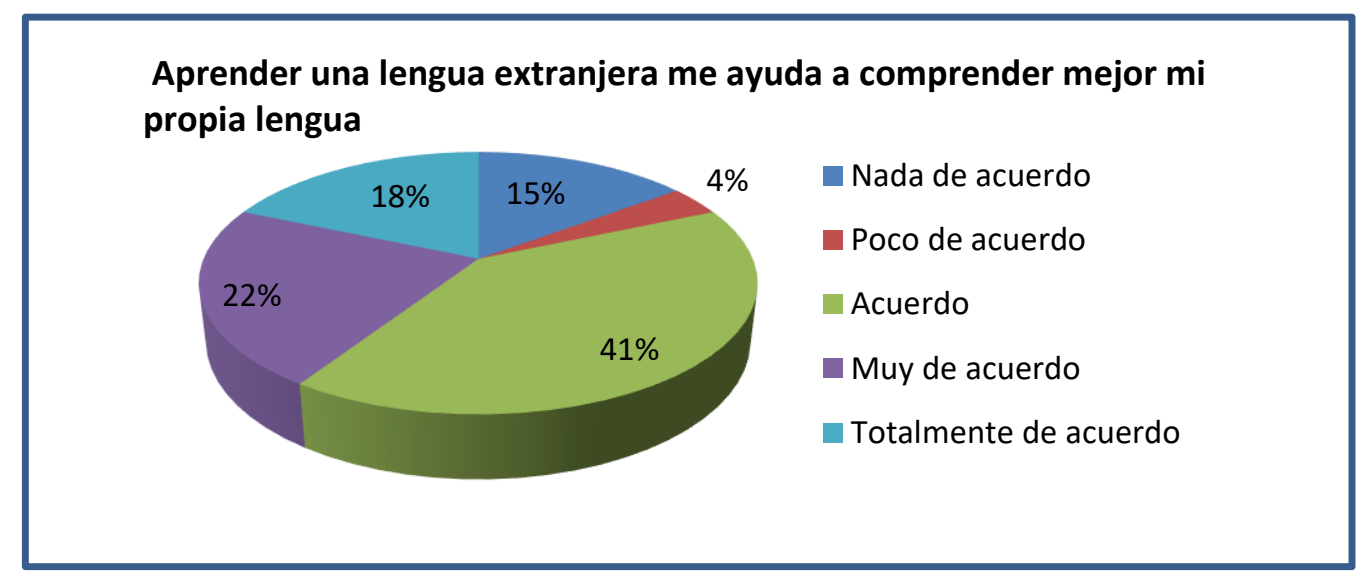

Figura 11. Encuesta realizada a alumnos del grupo bilingüe, pregunta 7 


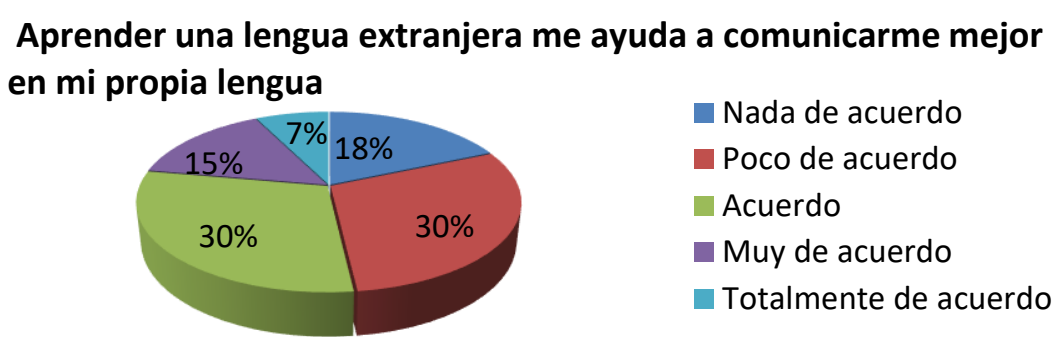

Figura 12. Encuesta realizada a alumnos del grupo bilingüe, pregunta 8

Con respecto a las estrategias que utilizan para aprender el idioma meta se constata que, con su integración en el programa, son conscientes de la necesidad de aprender el idioma de forma diferente a como lo venían haciendo en las clases tradicionales de instrucción formal. El $59 \%$ de los alumnos encuestados dice haber cambiado la forma de estudiar el idioma desde su incorporación al programa. Intentan imitar la pronunciación de hablantes nativos (85\%), aprender nuevas palabras y admite utilizar estrategias nuevas de compensación cuando no saben una palabra (82\%).

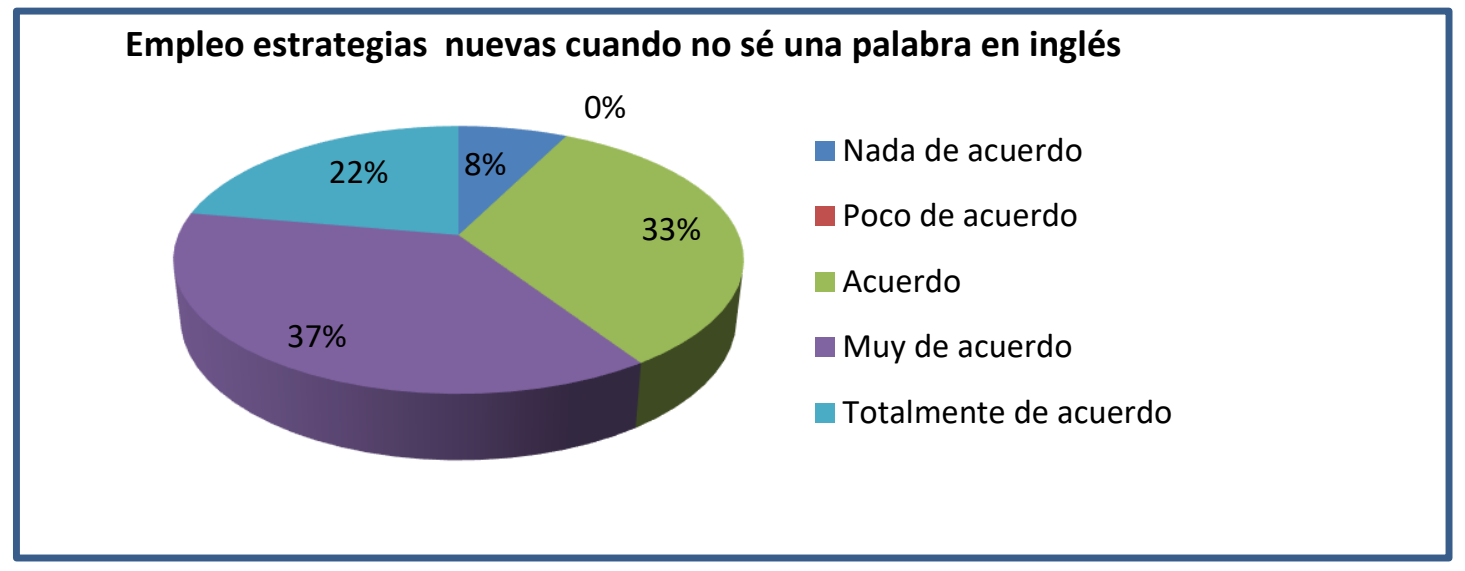

Figura 13. Encuesta realizada a alumnos del grupo bilingüe, pregunta17

Como dato a mejorar es la necesidad de incentivar más al alumnado a usar la lengua con más frecuencia para hablar con hablantes de otras lenguas y culturas pues solo un $55 \%$ admite hacerlo.

En resumen, los alumnos del grupo bilingüe están $100 \%$ satisfechos de participar en el programa, el $89 \%$ considera que habla mejor inglés desde que está en el programa bilingüe y aunque reconocen tener miedo a cometer errores al hablar, un $65 \%$, sin embargo, más de la mitad sigue prefiriendo recibir las clases de DNL (disciplinas no lingüísticas) en inglés.

Cuestionarios / entrevista a profesores del programa bilingüe: Los profesores que participan en el programa son, por una parte, profesores de Inglés como lengua extranjera y por otra, profesores de DNL, tales como Tecnología, Educación Física, Matemáticas, Música que tienen acreditado un nivel de competencia lingüística de B2 por la Administración Educativa. 
Los cuestionarios pasados a los profesores participantes en el programa bilingüe denotan un alto grado de implicación y compromiso de este para el buen funcionamiento del programa, su buena actitud, disposición y alto grado de interés para convertirlo en un programa de éxito académico. Todos ellos valoran positivamente la importancia de un programa de estas características para el centro educativo y lo recomiendan a sus amigos y familiares. Estos piensan que los alumnos que participan en estos programas están igualmente muy motivados para el estudio en general y para el aprendizaje de idiomas, y que llegan a alcanzar una elevada competencia comunicativa en el idioma vehicular, en este caso el inglés, gracias al programa.

Cabe destacar, sin embargo, que la mayoría demanda más medios y recursos por parte de la Administración para apoyar el programa, especialmente tras la reducción de las horas lectivas de instrucción formal en inglés. Indican la necesidad de formación en AICLE y de estancias formativas en el extranjero que mejoren sus destrezas en el idioma, así como el reconocimiento por parte de la Administración de un trabajo muy bien valorado por la Comunidad educativa de padres y profesores.

Señalan la conveniencia de mantener grupos reducidos de estudiantes que permitan interaccionar más con el profesor y aplicar las metodologías de los enfoques comunicativos y/ o de aprendizaje cooperativo, ampliar horarios de profesores nativos como auxiliares de conversación, todo ello encaminado a mejorar y conseguir el objetivo marcado por el Consejo de Europa.

Los profesores encuestados constatan, asimismo, el uso de estrategias de aprendizaje de la lengua extranjera y de los contenidos de las asignaturas AICLE, diferentes, son estrategias más productivas y variadas que aquellas de los alumnos que no siguen el enfoque AICLE. Igualmente, algunos manifiestan que los alumnos que siguen el programa afianzan mejor los contenidos de la asignatura impartida en inglés que aquellos que no siguen el programa. Es interesante, en este aspecto, señalar los valores muy positivos que arrojan las Pruebas de Diagnóstico de 2013 de los alumnos que siguieron el programa bilingüe en el estudio de la asignatura Conocimiento e Interacción con el Mundo Físico. Este constituirá el punto de partida de futuras líneas de investigación.

Como conclusión general extraída de esta triangulación de datos, comprobamos que la observación y evaluación inicial de la investigadora se ven refrendadas por los datos aquí obtenidos, no solo se produce una mejoría evidente en la expresión oral de los alumnos AICLE sino que, todo el contexto enseñanza -aprendizaje mejora por la alta motivación de los elementos implicados y redunda en una mejora cualitativa de los aprendizajes adquiridos.

Los alumnos del grupo bilingüe desarrollan la competencia de la expresión oral en inglés de forma más efectiva y diferente a como lo hacen en sus clases de inglés formal. El uso del inglés como lengua vehicular en las ANL no parece ser un obstáculo para afianzar los contenidos y los conceptos de las materias, todo lo contrario, el rendimiento de estos alumnos es mayor que el de los grupos no AICLE en estas materias.

\section{Discusión}

Recordamos a continuación la hipótesis formulada en el apartado de metodología de este trabajo: los programa AICLE / bilingües en inglés contribuyen de forma efectiva a la mejora de la expresión oral. 
En vista de los resultados obtenidos en el análisis de datos que vimos en el punto anterior, podemos concluir que se confirma esta hipótesis, podríamos decir que incluso se produce un mejor afianzamiento de los contenidos de las ANL en las que se usa el inglés como lengua vehicular, pero para ello necesitaríamos haber llevado a cabo un estudio más exhaustivo y profundo del tema, midiendo el progreso de estos alumnos del grupo experimental en un periodo de tiempo más extenso. Vemos a continuación cómo los resultados obtenidos apoyan la hipótesis de este trabajo.

\subsection{Pruebas de diagnóstico 2013}

Los resultados obtenidos en las pruebas de diagnóstico 2013 en los centros de Educación Primaria confirman la hipótesis inicial de la investigadora. De su análisis se desprende, pese al tamaño de los errores típicos y la pequeña $\mathrm{N}$, diferencias estadísticamente significativas entre los centros en todas las escalas menos precisamente en expresión oral en inglés, no obstante, la desviación típica de la media en el centro bilingüe es bastante superior al del centro no bilingüe, por lo que se puede interpretar como un grupo más heterogéneo. No sorprende este dato a la investigadora, pues son las destrezas receptivas las que más se desarrollan durante los primeros estadios de la enseñanza AICLE.

De la lectura e interpretación del resto de los datos se desprende, como era esperable, una mejora muy significativa en las destrezas receptivas de comprensión oral y escrita de los alumnos bilingües respecto de los no bilingües. Además, es destacable que la asignatura de Conocimiento e Interacción con el Mundo Físico, precisamente la que se imparte usando la lengua inglesa como vehicular en el centro bilingüe, alcanza unos niveles de adquisición muy superiores a los que logran los alumnos del centro no bilingüe.

Veamos si los demás resultados de la investigación siguen la línea y los datos esperados por la investigadora; ie; mejora de la expresión oral en los estadios más tardíos de la enseñanza-aprendizaje AICLE.

\subsection{Pruebas objetivas de expresión oral}

Los resultados de las pruebas de expresión oral aplicadas al grupo experimental de alumnos confirman la hipótesis de la investigación. Recordemos que ambos grupos, el experimental y el de control, objeto de estas pruebas de expresión oral son los mismos que los de las pruebas de diagnóstico 2013 de los colegios de primaria adscritos al IES.

De la lectura de los resultados se confirma la evolución ascendente de las calificaciones de los alumnos que siguen el programa bilingüe. Por el contrario, las calificaciones del grupo no bilingüe son muy variables y tienen una evolución muy negativa. Los alumnos de bilingüe en su mayoría, el 70 \%, mejoran sus calificaciones en expresión oral en la 2. evaluación respecto a la 1.․, solo un 30 \% empeora o baja su rendimiento. Además, la desviación típica es baja por lo que las diferencias entre los rendimientos de los diferentes alumnos no son significativas, por el contrario, la desviación típica de los alumnos no bilingües es bastante superior a la de no bilingües, lo que nos da idea de que el grupo no bilingüe es bastante heterogéneo.

El promedio de calificaciones de expresión oral del grupo bilingüe es de 7,32el del grupo no bilingüe es de 4,68. Con esto, podemos afirmar que los programas bilingües / AICLE 
promueven significativamente el desarrollo de la competencia en expresión oral de los alumnos, que mejora con el paso del tiempo.

\subsection{Cuestionarios a padres, alumnos y profesores del programa}

bilingüe, AICLE

Los resultados obtenidos tras la tabulación de las respuestas sorprenden a la investigadora. Las respuestas a las preguntas de tipo escala de intensidad demuestran la satisfacción de padres, alumnos y profesores con el programa bilingüe, ya que los porcentajes más altos se encuentran en el punto final de la escala.

El análisis exhaustivo de las respuestas (mixtas, abiertas) es relevante para determinar la hipótesis de este trabajo, el $71 \%$ de los padres consideran que la formación impartida en el programa bilingüe es buena, un $84 \%$ de los padres considera que la expresión oral de su hijo ha mejorado sustancialmente dentro del programa bilingüe. El $100 \%$ de los alumnos encuestados valoran su nivel del inglés como medio o alto, el $81 \%$ considera que aprender una lengua extranjera le ayuda a comprender mejor su lengua materna, al $56 \%$ le gusta aprender otras asignaturas en inglés, lo que contribuye a aumentar la motivación y el interés de los alumnos y con ello a mejorar el proceso de enseñanza-aprendizaje, el $85 \%$ se siente seguro cuando habla en público en inglés, el $89 \%$ cree que habla mejor inglés desde que está en el programa y el $92 \%$ utiliza estrategias nuevas cuando no sabe una palabra en inglés.

Por otra parte, el cuestionario a profesores revela que los alumnos que siguen el programa alcanzan una elevada competencia comunicativa en inglés y que estos alumnos usan estrategias de aprendizaje del idioma distintas a los que no lo siguen. Los profesores en las preguntas abiertas coinciden en demandar más apoyo de las administraciones educativas, ampliando recursos en personal y en formación, necesidades que son suplidas con el esfuerzo de todo el profesorado implicado en este tipo de programa de innovación educativa. Destaca la valoración muy positiva que hacen los docentes del programa pues el $100 \%$ de los encuestados recomendaría el programa.

Con estos resultados se vuelve a nuestra hipótesis de investigación y comprobamos que la expresión oral sí mejora en los programas AICLE / bilingües y que los alumnos usan estrategias de aprendizaje diferentes a los que no siguen el programa.

\section{Conclusiones}

Este trabajo de investigación muestra que la enseñanza bilingüe / AICLE mejora notablemente la competencia comunicativa en lengua extranjera de los estudiantes pero es necesario seguir investigando qué factores (motivación alta de los estudiantes y comunidad educativa en general, diferente enfoque en la enseñanza de lenguas, más medios y recursos, uso de las NTIC, anticipación en la edad para aprender el idioma extranjero) son los que determinan esta mejoría dentro del programa AICLE / bilingüe y así seguir haciendo cambios y adaptaciones en la metodología actual en la enseñanza de idiomas para lograr un pleno desarrollo de la expresión oral en nuestros alumnos de lenguas extranjeras.

Tradicionalmente España ha sido un país con un bajo nivel de competencia comunicativa en la expresión oral de los estudiantes de inglés a pesar de haber dedicado años al estudio del idioma. Esta tendencia parece que está cambiando y las actuales generaciones de estudiantes 
que siguen el programa AICLE/ bilingüe logran un nivel B1 en el idioma según el MCERL en la etapa de Educación Secundaria Obligatoria, superándolo incluso antes de finalizar la etapa. Por esto, podemos concluir afirmando que nuestros estudiantes son conscientes de la importancia que tiene aprender a comunicarse en un idioma, hecho que hace que nos estemos aproximando a los índices medios europeos en el dominio de lenguas extranjeras y mejorando el éxito de la movilidad de los estudiantes españoles.

Este dato esperanzador nos anima a querer seguir investigando sobre el tema con dos líneas claras: factores que favorecen el desarrollo de la expresión oral en la enseñanza de idiomas y qué cambios es necesario abordar desde los distintos niveles de concreción curricular para lograr hacer ciudadanos competentes en una lengua extranjera.

\section{Referencias bibliográficas}

ALLWRIGHT, R., ALLWRIGHT, D., \& BAILEY, K. M. (1991). Focus on the language classroom: An introduction to classroom research for language teachers. Cambridge University Press.

ATKINSON, J. W. (1964). An introduction to motivation. Princeton, NJ: Van Nostrand.

BISQUERRA, R. (1989). Métodos de investigación educativa: Guía práctica. Barcelona: CEAC.

BRUTON, A. (2011). Are the differences between CLIL and non-CLIL groups in Andalusia due to CLIL? A reply to Lorenzo, Casal and Moore (2010). Applied Linguistics, 32(2), 236-241.

CAÑADO, M. L. P. (2017). Stopping the "pendulum effect" in CLIL research: Finding the balance between Pollyanna and Scrooge. Applied Linguistics Review, 8(1), 79-99.

COONAN, C. M. (2006). La metodologia task-based e CLIL. Il futuro si chiama CLIL. Una ricerca interregionale sull'insegnamento veicolare, Provincia Autonoma di Trento.

COYLE, D., HOOD, P., \& MARSH, D. (2010). Content and language integrated learning. Ernst Klett Sprachen.

DALTON-PUFFER, C. (2011). Content-and-Language Integrated Learning: From Practice to Principles?. Annual Review of Applied Linguistics, 31, 182-204. doi:10.1017/S0267190511000092

CONSEJO DE EUROPA. (2001). Marco Común Europeo de Referencia para las Lenguas: aprendizaje, enseñanza, evaluación. Madrid: Instituto Cervantes/Ministerio de Educación, Cultura y Deporte/Anaya, 2002.

KEMMIS, S., \& McTAGGART, R. (1988). The action research planner. London/New York: Springer.

LASAGABASTER, D. L., \& DE ZAROBE, Y. R. (2010). Ways forward in CLIL: Provision issues and future planning. In CLIL in Spain: Implementation, results and teacher training (pp. 278-295). Cambridge Scholars Publishing.

MARSH, D., CAÑADO, M. L. P., \& PADILLA, J. R. (Eds.). (2015). CLIL in Action: Voices from the Classroom. Cambridge Scholars Publishing.

MINISTERIO DE EDUCACIÓN (20110-2011). Plan de Acción Inmediata 2010-2011. Objetivos de la Educación para la década 2010-2020. Ministerio de Educación. [Consultado 10/04/2020] [Recuperado de: http://www.educacion.es/dctm/ministerio/horizontales/prensa/documentos/2010/p lan-de-accion-2010-2011vdefinitivafinal.pdf?documentId=0901e72b801b3cad.] 
MURILLO, F.J. (2006). Retos de la innovación para la investigación educativa. En T. ESCUDERO y A.D. CORREA (Coords.), Innovación e investigación educativa: algunos ámbitos relevantes (pp. 23-54). Madrid: La Muralla.

NUNAN, D. (1992). Research methods in language learning. Cambridge: Cambridge University Press.

NÚÑEZ, J. C. (2009). Motivación, aprendizaje y rendimiento académico. En $X$ Congresso Internacional Galego-Português de Psicopedagogia. Braga, Portugal (pp. 41-67).

RUIZ DE ZAROBE, Y. (2011). Which language competencies benefit from CLIL? An insight into applied linguistics research. Content and foreign language integrated learning: Contributions to multilingualism in European contexts, 129-154.

VALLE, A., RODRÍGUEZ, S., CABANACH, R. G., NÚÑEZ, J. C., \& GONZÁLEZ-PIENDA, J. A. (2007). El estudiante eficaz. Madrid: CCS.

VAN LIER, L. (1988). The classroom and the languagvalle e learner: Ethnography and secondlanguage classroom research. London: Longman. 